\title{
Cálculo e análise da carga térmica da Biblioteca Diva Saraiva do Campus I da FACTHUS - Uberaba/MG
}

\section{Calculation and analyze of the thermal load from the Diva Saraiva Library from Campus I from the FACTHUS - Uberaba/MG}

\author{
Leandro Ribeiro Alves ${ }^{1}$; José Braz de Araújo Júnior ${ }^{2}$; Felipe Santos Moreira ${ }^{3}$ \\ ${ }^{1}$ Engenheiro Mecânico, Faculdade de Talentos Humanos - FACTHUS, Universidade Federal do Triângulo \\ Mineiro - UFTM, Uberaba, MG, Brasil. \\ Orcid: http://orcid.org/0000-0003-0711-6850.E-mail: leandro.alves@uftm.edu.br \\ ${ }^{2}$ Engenheiro Mecânico, Faculdade de Talentos Humanos - FACTHUS, Uberaba, MG, Brasil. \\ E-mail: junin_8@outlook.com \\ ${ }^{3}$ Professor, Doutor em Engenharia Química, Faculdade de Talentos Humanos - FACTHUS, Uberaba, MG, \\ Brasil. Orcid: http://orcid.org/0000-0001-8098-1387. E-mail: felipe.moreira@facthus.edu.br
}

\begin{abstract}
RESUMO: A climatização de ambientes visa controlar o clima de um ambiente fechado, condicionando o ar de forma a ajustar a temperatura, umidade, velocidade e pureza, para padrões de conforto térmico e de controle de poluentes, estabelecidos por resoluções e normas técnicas. Na Biblioteca Diva Saraiva do Campus I da Faculdade de Talentos Humanos, situada na cidade de Uberaba/MG, foi notado desconforto térmico por grande parte dos usuários. Os livros e demais arquivos da biblioteca encontram-se expostos a flutuações de temperatura e umidade, que favorecem a proliferação de fungos, que por consequência, aceleram os processos de deterioração de arquivos em papéis. $O$ presente artigo apresenta uma abordagem do cálculo de carga térmica de uma edificação, a partir de três situações críticas: máxima irradiação solar, máxima temperatura externa e máxima ocupação de pessoas. A maior carga térmica encontrada foi na situação de máxima temperatura do ar externo, com o valor de 38.760,95 W, sendo que as maiores parcelas foram de condução de calor pela envoltória e renovação de ar. Foi proposta a instalação de um sistema VRF de climatização contendo 7 unidades evaporadoras, sistema de renovação de ar e também a aquisição de 2 desumidificadores portáteis para garantir a umidade relativa apropriada atendendo às demandas encontradas da edificação, acompanhado dos custos de aquisição $(R \$ 122.608,00)$, instalação $(R \$ 50.000,00)$ e manutenção dos equipamentos ( $R \$ 2.800,00$ mensais).
\end{abstract}

Palavras-chave: Climatização de Bibliotecas; Conforto Térmico; Irradiação Solar; Ventilação.

ABSTRACT: The climatization of environments aims to control the climate of a closed environment, conditioning the air to adjust the temperature, humidity, velocity, and purity to standards of thermal comfort and control of pollutants, established by resolutions and technical norms. At the Diva Saraiva Library on Campus I of the Faculty of Human Talents, located in the city of Uberaba/MG, thermal discomfort was noticed by most users. Books and other library files are exposed to fluctuations in temperature, and humidity that favor the proliferation of fungi, which consequently accelerate the processes of deterioration files papers. This work presents an approach to the thermal load calculation of a building, from three critical situations: maximum solar radiation, maximum external temperature and a maximum occupancy of people. The greatest thermal load was found in the position of the maximum temperature of the outdoor air, the value of $38760.95 \mathrm{~W}$, with the largest portions, were heat conduction and the envelope air renewal. It has been proposed to install a VRF cooling system containing 7 evaporator units, 1 air exchange system, and also the acquisition of 2 portable dehumidifiers to ensure relative humidity appropriate meeting the demands of the building found, accompanied by the acquisition costs $(R \$ 122,608.00)$, installation $(R \$ 50,000.00)$ and maintenance of equipment ( $R \$ 2,800.00$ monthly).

Keywords: Air Conditioning of Libraries; Thermal Comfort; Solar Irradiation, Ventilation. 
Revista Brasileira de Ciência, Tecnologia e Inovação

\section{INTRODUÇÃO}

A refrigeração aparece em diversas atividades humanas e pode ser utilizada para fins domésticos, comerciais e industriais como, por exemplo, os refrigeradores, congelamento de alimentos e climatização de ambientes, etc. (SILVA, 2010).

De acordo com Silva (2010), climatizar um local fechado, é um processo de tratamento do ar, a fim de controlar simultaneamente a temperatura, umidade, pureza e a movimentação do ar no ambiente. A Carga Térmica (CT) consiste em todo o calor que precisa ser removido de um ambiente climatizado, para manter constantes as condições desejadas de temperatura e umidade internas, através de meios mecânicos. Refrigeração é o nome dado a essa retirada de calor do ambiente.

As principais variáveis climáticas que são analisadas para os padrões de conforto térmico são a umidade, temperatura, velocidade do ar e radiação solar incidente, pois estão relacionadas com o funcionamento do corpo humano, cujo mecanismo é complexo e pode ser, de modo geral, comparado com uma máquina que produz calor de acordo com sua atividade. Um ser humano saudável libera calor para manter sua temperatura corporal interna de $37^{\circ} \mathrm{C}$. Quando isso acontece sem grande esforço, causa sensação de conforto térmico (FROTA; SCHIFFER, 2001).

Outra grande fonte de calor para um ambiente a que se pretende climatizar é a temperatura e movimentação do ar externo, que acaba transmitindo calor por convecção, além da irradiação térmica provinda da vizinhança, penetrando por meio da condução térmica para o ambiente interno (SACHT; ROSSIGNOLO; SANTOS, 2010).

O ser humano tem uma melhor condição de vida quando seu organismo consegue funcionar sem fadiga ou estresse, que podem ser gerados por diversos fatores, inclusive 0 calor e o frio excessivos. Portanto, a arquitetura tem como uma de suas funções fornecer condições de conforto térmico no interior das construções civis, independentemente das condições do clima externo (FROTA; SCHIFFER, 2001).

Algumas tecnologias introduzidas atualmente na construção civil geram dúvidas a respeito da qualidade de vida nas edificações. As habitações devem fornecer conforto e segurança aos seus habitantes. Ao longo dos últimos anos vários países se empenharam para aumentar o embasamento científico para melhorar 0 desempenho do condicionamento de ar em edificações. No Brasil esse tema vem ganhando espaço, pois se tem uma grande preocupação com um desempenho mínimo nas edificações e foi expressa de forma documental na publicação da Norma Brasileira Regulamentadora (NBR) 15575 de 2013, que estabelece requisitos mínimos de desempenho, vida útil e de garantia para os principais sistemas que compõem as edificações (SORGATO et al., 2014).

A falta de preocupação com o clima nas construções civis evidencia problemas, como, a estética de fachadas e o desconforto térmico de usuários das edificações (BRAGA; AMORIM, 2004).

A análise dos picos de carga térmica em edificações tem influência direta para um dimensionamento correto de um sistema de condicionamento térmico artificial, e no Brasil tem se dado pouca importância para a construção e orientação de paredes e coberturas, o que acaba levando uma parede a atuar como um painel radiante em determinadas horas do dia (GRANJA; LABAKI, 2004).

Segundo Cassares (2000), a climatização de ambientes fechados que possuem grande quantidade de documentos em papel, como por exemplo em uma biblioteca, a não 
Revista Brasileira de Ciência, Tecnologia e Inovação

observação das normas relacionadas a calor e umidade, contribuem para deterioração dos documentos. A velocidade em que acontece a deterioração, é dobrada a cada aumento de $10 \stackrel{\circ}{ } \mathrm{C}$ e o aumento da umidade proporciona condições que contribuem para essa aceleração. Estas situações proporcionam condições que são favoráveis para desencadear reações químicas e físicas nos materiais em papel, pois poluentes, assim como agentes biológicos (insetos, roedores e fungos) necessitam de umidade para sua sobrevivência e proliferação, que contribuem significativamente para a deterioração dos acervos e arquivos.

Conforme Branco (2016), a correta conservação de documentos em papel é complexa, devido as reações que os deterioram os mesmos de forma natural. Mantendose níveis adequados de determinados parâmetros, é possível apenas retardar esse processo de degradação. Conhecer a idade dos documentos que estão guardados, é de suma importância, pois em uma biblioteca onde apenas se leem livros, os cuidados para conservar os acervos são diferentes quando comparados a um arquivo/museu importante contendo obras mais antigas e raras. Cortes de despesas e custos de conservação são comuns a um projeto de edificação quando o mesmo ultrapassa o valor definido de projeto, e esses cortes muitas vezes são direcionados ao sistema de climatização, prejudicando-o de tal maneira que, em alguns casos, torna-o pior do que não ter um sistema de ar condicionado.

Neste contexto, o objetivo do presente trabalho foi calcular a CT da Biblioteca Diva Saraiva sob três situações críticas, em instantes de: máxima irradiação solar; máxima temperatura externa e máxima ocupação. Por conseguinte, propor a instalação de um sistema de climatização que atenda os parâmetros requisitados pela edificação, informando os custos de aquisição, instalação e manutenção dos equipamentos.

\section{REVISÃO DA LITERATURA}

O método de cálculo RTSM (Radiant Time Series Method) corresponde ao descrito pela American Society of Heating, Refrigerating and Air-Conditioning Engineers (ASHRAE) em sua publicação HVAC Fundamentals entre os anos de 2001 ao 2013.

Segundo Nardelli (2018), o método RTSM não requer cálculos iterativos, contudo oferece como resposta um resultado confiável. O objetivo principal é obter a carga térmica total horária. Para isso, as frações convectivas previamente calculadas da CT são adicionadas as frações por ganho de calor radiante através de transmissão solar, condução através de superfícies e de fontes internas de calor para determinada hora analisada.

Autores como Creder (2004), Silva (2010), Lamberts, Dutra e Pereira (2014), entre outros, utilizam a ASHRAE HVAC Fundamentals como referência em suas metodologias de cálculo de carga térmica. As parcelas que compõem a CT são:

- Insolação: Calor que penetra no ambiente interno devido à irradiação solar que incide sobre as superfícies opacas e translúcidas da envoltória da edificação;

- Condução: Calor que penetra no ambiente interno através de superfícies opacas e translúcidas devido à diferença de temperatura entre as partes externa e interna da edificação;

- Pessoas: Calor liberado por ocupantes do ambiente;

- lluminação artificial e equipamentos: Calor liberado por lâmpadas e equipamentos elétricos instalados dentro do recinto; 


\section{RBCTI}

- Infiltração de ar: Corresponde ao ar que entra no ambiente interno por meio de frestas de portas e janelas.

- Renovação de ar: A carga térmica de renovação corresponde a quantidade de ar que necessita ser inserida/retirada mecanicamente no ambiente para diluir a concentração de poluentes (físicos, químicos e biológicos) do ar, mantendo-o em níveis aceitáveis (NBR 16401-1, 2008).

Conforme Creder (2004), a carga térmica total também pode ser dividida em sensível e latente. A parte sensível representa a energia calorífica que precisa ser removida do ambiente para manter-se a temperatura interna no valor desejado. Já a parte latente representa a quantidade de vapor d'água que necessita ser removida do ambiente para manter-se a umidade relativa interna nos parâmetros estipulados.

De acordo com Trinkley (2001), o programa de construção ou reforma de uma biblioteca deve proporcionar um equipamento de climatização que ajude a preservação dos materiais bibliográficos, mantendo níveis apropriados de temperatura e umidade, fornecendo um ar limpo e filtrado, contribuindo com a redução de poluentes no ar. Os parâmetros recomendados de temperatura e umidade relativa do ar para uma biblioteca são respectivamente $18{ }^{\circ} \mathrm{C}$ a $24{ }^{\circ} \mathrm{C}$ e $45 \%$ a $55 \%$.

Instalar um ou mais equipamentos de desumidificação, é a estratégia mais efetiva quando o usuário necessita de um melhor controle da umidade relativa. $O$ ar condicionado, controlado por um termostato, e o desumidificador, controlado por um umidostato, fazem o controle de forma independente dos parâmetros de temperatura e umidade, garantindo um controle ajustado sem haver desperdício de energia (ALMEIDA, 2018).

\section{MÉTODO}

Para analisar e propor um sistema de climatização para a Biblioteca Diva Saraiva do Campus I da Faculdade de Talentos Humanos em Uberaba/MG, foi realizado um levantamento de todos os dados relevantes para os cálculos do projeto, para que fosse efetuada a estimativa mais fiel possível ao modelo real da CT da edificação.

A base de dados climáticos e a localização da edificação, foram as primeiras informações verificadas para se iniciar o projeto de climatização. A Biblioteca Diva Saraiva do Campus I da Faculdade de Talentos Humanos encontra-se na Cidade de UberabaMG, na rua Manoel Gonçalves Rezende no 230 no bairro São Cristóvão. As informações de localização e orientação geográfica são mostradas na Tab. 1 e Fig. 1.

Tabela 1. Posição geográfica da biblioteca.

\begin{tabular}{llll}
\hline Localização & Latitude & Longitude & Elevação \\
\hline Biblioteca Diva Saraiva & $-19,776^{\circ}$ & $-47,938^{\circ}$ & $809 \mathrm{~m}$ \\
\hline${ }^{*}$ Fonte: Google Mapas, 2019. & & &
\end{tabular}

Foram coletados no site do Instituto Nacional de Meteorologia (INMET, 2019) dados climáticos atuais da estação meteorológica automática da Universidade Federal do Triângulo Mineiro (UFTM), situada na cidade de Uberaba-MG.

Como referência de dados climáticos, foi analisado o período entre 01/09/2018 e $31 / 03 / 2019$, no qual apresentam os dias de insolação e temperatura mais elevados em Uberaba/MG (INMET, 2019). Esse período foi escolhido sabendo que o projeto deve ser 
dimensionado para situações mais críticas do ano, sendo assim atenderia os períodos com menores índices de CT.

Figura 1. Orientações das Paredes.

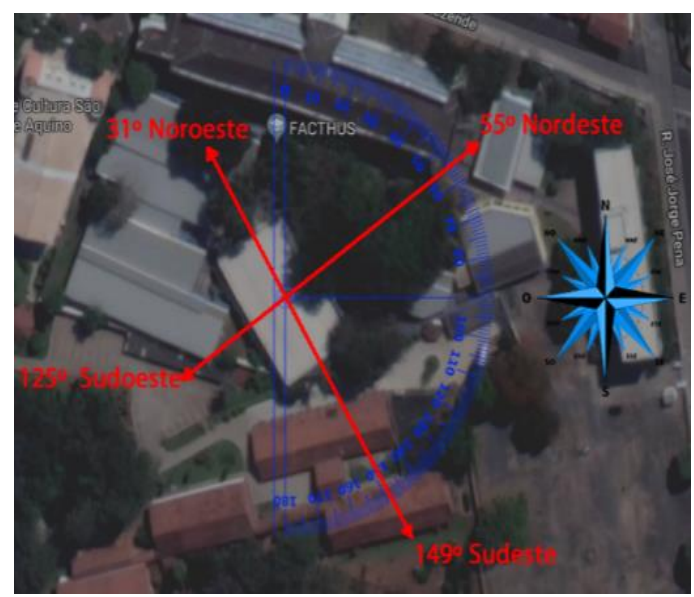

Fonte: Adaptado de Google Mapas, 2019.

A tabela de dados gerados pelo INMET foi reclassificada em três partes: Situação 1, constituiu instantes de máxima irradiação solar. Situação 2, foram instantes de máxima temperatura. Situação 3, instantes de máxima ocupação para a Biblioteca Diva Saraiva.

Como a máxima irradiação não ocorre no horário da máxima temperatura, que também não é no mesmo instante de máxima ocupação, tornou-se pertinente analisar sob esses três pontos de vista para identificar como a envoltória se comporta em cada um deles, definindo qual o mais impactante para os maiores valores de CT.

Após organizadas as tabelas de forma decrescente, e de acordo com o estudo de interesse, foram selecionados apenas as primeiras 50 linhas de cada condição. A Tab. 2 traz uma amostra dos dados. Essa decisão foi porque prolongar a seleção não agregaria valor à análise final da carga térmica, visto que os dados estão organizados de forma decrescente, dando foco aos instantes mais críticos.

Tabela 2. Amostra dos dados climáticos organizados decrescentemente por temperatura.

\begin{tabular}{ccccc}
\hline Data & Hora real & Temperatura $\left[{ }^{\circ} \mathrm{C}\right]$ & Umidade $[\%]$ & Radiação Solar $\left[\mathrm{W} / \mathrm{m}^{2}\right]$ \\
\hline 24/09/2018 & $16: 00$ & 35,2 & 21 & 566,11 \\
24/09/2018 & $14: 00$ & 35,0 & 20 & 927,78 \\
24/09/2018 & $15: 00$ & 34,9 & 20 & 785,56 \\
24/09/2018 & $13: 00$ & 34,6 & 23 & 921,94 \\
01/02/2019 & $14: 00$ & 34,3 & 32 & $1.066,11$ \\
25/09/2018 & $15: 00$ & 34,3 & 28 & 798,33 \\
31/01/2019 & $16: 00$ & 34,3 & 34 & 5833,89 \\
$31 / 01 / 2019$ & $15: 00$ & 34,1 & 33 & 987,50 \\
$01 / 02 / 2019$ & $16: 00$ & 34,0 & 31 & 807,78 \\
26/09/2018 & $16: 00$ & 34,0 & 27 & 585,28 \\
\hline
\end{tabular}

Para trabalhar com os dados construtivos da edificação, a biblioteca foi dividida em dois espaços distintos, sendo a Parte $A$, que compreende a área onde ficam alocados 
Revista Brasileira de Ciência, Tecnologia e Inovação

os livros, computadores de mesa e a maioria dos ocupantes, e a Parte B que corresponde às duas pequenas salas com divisórias de vidro situadas à direita da edificação, como pode ser visto na Fig. 2. Suas respectivas medidas são mostradas na Tab. 3.

Figura 2. Partes A e B da biblioteca.

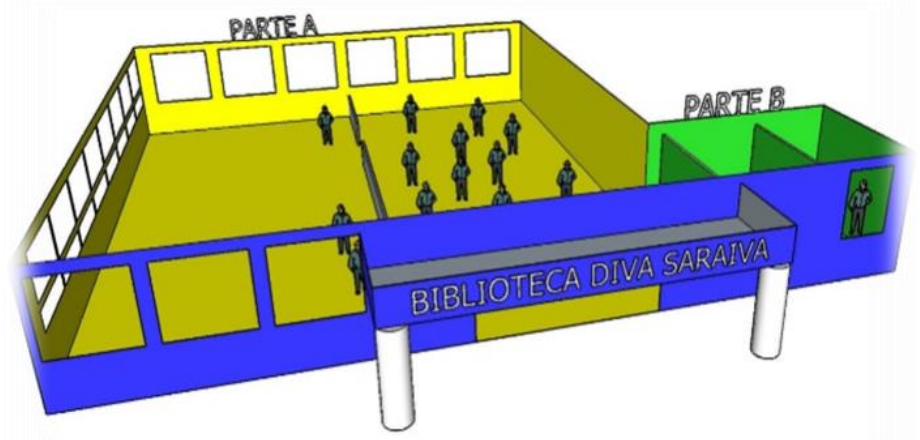

Tabela 3. Áreas e pé-direito da biblioteca.

\begin{tabular}{cccc}
\hline Área da Parte $\mathrm{A}\left(\mathrm{m}^{2}\right)$ & Área da Parte B $\left(\mathrm{m}^{2}\right)$ & Área total $\left(\mathrm{m}^{2}\right)$ & Pé-direito $(\mathrm{m})$ \\
\hline 402,8 & 35,1 & 437,9 & 3,8 \\
\hline
\end{tabular}

Todos os dados foram subdivididos de acordo com o norte verdadeiro, sendo os lados Sudoeste (SO), Sudeste (SE), Nordeste (NE) e Noroeste (NO). Em ambas as partes foram realizadas as medições da área e altura do local, tamanho das janelas e portas.

Existe uma porta de vidro localizada na parede NE da Parte A, com largura de 5,8 $\mathrm{m}$ e altura de $2,45 \mathrm{~m}$, onde foi recomendado que a mesma fique fechada para evitar grande penetração de calor no ambiente pelo ar externo. A porta deverá ser aberta na passagem de algum ocupante e fechada logo em seguida.

Figura 3. Lateral Direita (SE) da Biblioteca.

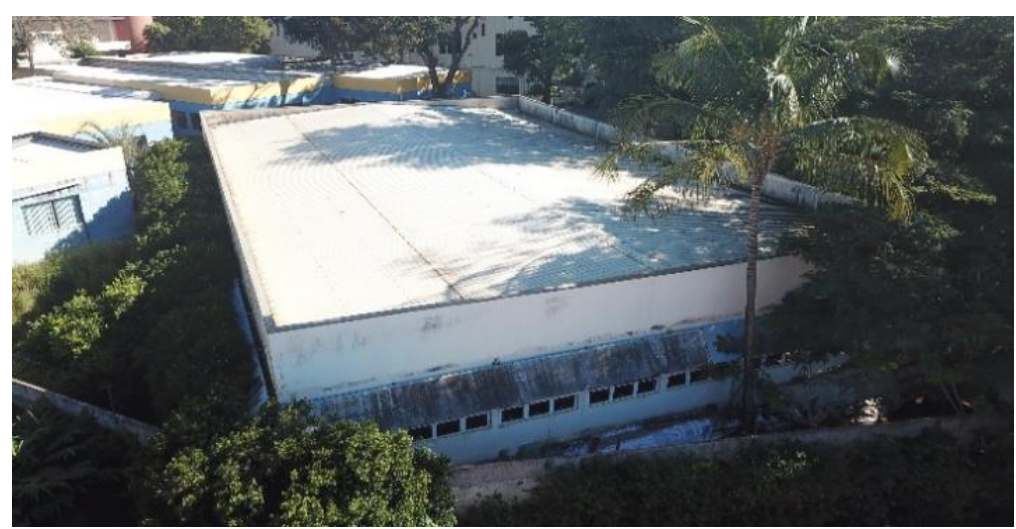

É importante ressaltar que a parede NO da Parte A e a parede SO da Parte B, fazem fronteira com um ambiente climatizado à mesma temperatura (centro administrativo da faculdade). Isto faz com que não haja transferência de calor por condução e insolação. 
Por consequência, estas paredes são desconsideradas do cálculo da CT. As paredes externas, cobertura e espaço interno são apresentadas nas Fig. $\mathbf{3}$ a 5.

Figura 4. Fundo da Biblioteca (SO)

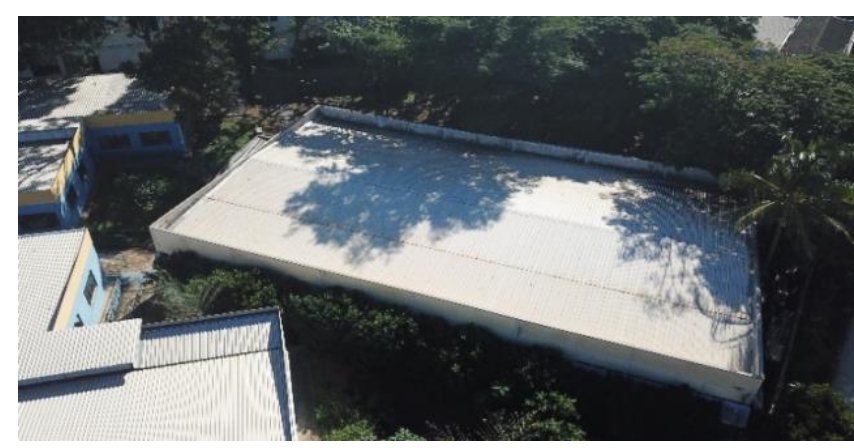

Figura 5. Espaço interno da Biblioteca.

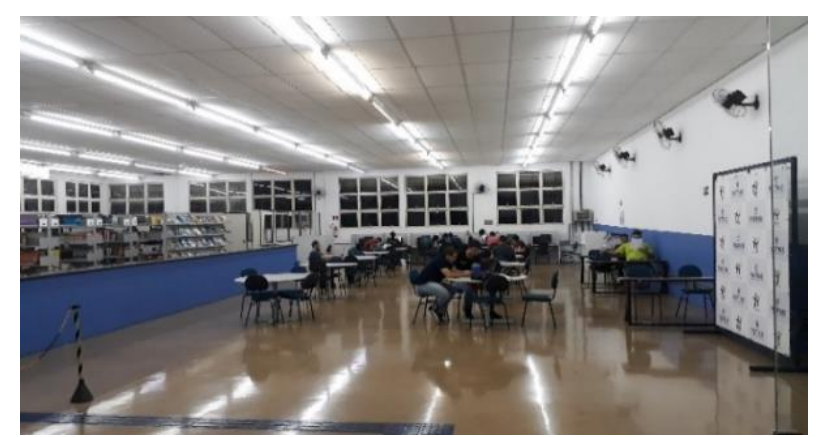

\section{Carga Térmica de Insolação $\left(Q_{\text {ins }}\right)$}

Segundo Lamberts, Dutra e Pereira (2014), a quantidade de calor transferido por insolação $\left(Q_{\text {ins }}\right)$ em Watts que entra num recinto difere entre superfícies opacas e translúcidas, e são dadas pelas equações (1) e (2).

$$
Q_{\text {ins }} \text { (opacas) }=U * A *\left(\alpha * R_{s e} * I\right)
$$

em que, $U$ representa o Coeficiente global de transmitância térmica $\left(\mathrm{W} / \mathrm{m}^{2} . \mathrm{K}\right) ; A$ é a Área da superfície $\left(\mathrm{m}^{2}\right)$; $\alpha$ é a Absortividade da superfície externa; $R_{s e}$ é a Resistência superficial externa onde incidem os raios solares $\left(\mathrm{m}^{2} . \mathrm{K} / \mathrm{W}\right)$ e $/$ é a Irradiação solar incidida na superfície $\left(\mathrm{W} / \mathrm{m}^{2}\right)$.

$$
Q_{\text {ins }}(\text { translúscidas })=A *(F S * I)
$$

em que, FS representa o Fator Solar do material e da proteção solar.

A quantidade de irradiação solar (I) que incide em todas as superfícies da envoltória conforme o horário e dia do ano, foi calculada seguindo a metodologia de Creder (2004).

A construção das paredes da Biblioteca Diva Saraiva é composta por: bloco de concreto $\left(1,4 \times 10^{-1} \mathrm{~m}\right)$; reboco de argamassa $\left(2,5 \times 10^{-2} \mathrm{~m}\right)$; pintura. Estas condições se enquadram no tipo de parede no 8 do Anexo Geral V, da Portaria 50/2013 do Inmetro, possuindo um coeficiente global de transmitância térmica $(U)$ de $2,87 \mathrm{~W} / \mathrm{m}^{2} . \mathrm{K}$.

A cobertura da biblioteca é composta por: telha termo acústica (chapa de zinco $1,00 \times 10^{-3} \mathrm{~m}$, poliestireno moldado $3,00 \times 10^{-2} \mathrm{~m}$, chapa de zinco $1,00 \times 10^{-3} \mathrm{~m}$ ); câmara de $\operatorname{ar}\left(>5,00 \times 10^{-2} \mathrm{~m}\right)$ com fluxo de calor descendente e não ventilada; forro de placas de isopor $\left(3,00 \times 10^{-2} \mathrm{~m}\right)$. O coeficiente global de transmitância para esse tipo de cobertura não foi encontrado na literatura, portanto, foi calculado utilizando os dados da Tab. 4, apresentando um coeficiente $(\mathrm{U})$ de $4,7 \times 10^{-1} \mathrm{~W} / \mathrm{m}^{2} . \mathrm{K}$. 
Revista Brasileira de Ciência, Tecnologia e Inovação

Tabela 4. Propriedades dos materiais da cobertura.

\begin{tabular}{|c|c|c|}
\hline Material & $\lambda(\mathrm{W} / \mathrm{m} . \mathrm{K})$ & $R_{a r}\left(\mathrm{~m}^{2} . \mathrm{K} / \mathrm{W}\right)$ \\
\hline Zinco & $1,12 \times 10^{2}$ & - \\
\hline $\begin{array}{c}\text { Poliestireno expandido } \\
\text { Moldado }\end{array}$ & $4,00 \times 10^{-2}$ & - \\
\hline Câmara de ar $>5 \mathrm{~cm}$, não ventilada, fluxo de calor descendente. & - & $6,10 \times 10^{-1}$ \\
\hline
\end{tabular}

Fonte: Adaptado de NBR 15220, 2003.

Na Biblioteca Diva Saraiva a cobertura e as paredes sudeste (SE) possuem tintura na cor branco gelo com coeficiente a de 37,2; as paredes sudoestes (SO) têm tintura aproximada ao amarelo canário, correspondente a $\alpha$ de 29,3; e as paredes nordestes (NE) possuem tintura azul imperial com $\alpha=66,9$ (INMETRO,2013).

As superfícies translúcidas da biblioteca são formadas por vidros de espessura média de $5 \mathrm{~mm}$, FS de 0,85 e coeficiente $(\mathrm{U})$ de aproximadamente $6,0 \mathrm{~W} / \mathrm{m}^{2}$.K. As janelas de orientação sudeste (SE) e sudoeste (SO) são protegidas por toldos opacos à 45으, FS de 0,2 . Quanto à orientação nordeste (NE), há uma cobertura opaca da fachada do prédio e árvores que cobrem aproximadamente $50 \%$ da área envidraçada.

Carga Térmica de Condução $\left(Q_{c o n d}\right)$

Para a CT de condução, segundo Lamberts, Dutra e Pereira (2014), a taxa de transferência de calor por condução $\left(Q_{\text {cond }}\right)$ para paredes, coberturas e janelas é expressa pela equação (3):

$$
Q_{\text {cond }}=U * A *\left(T_{\text {ext }}-T_{\text {int }}\right)
$$

em que, $T_{\text {ext }}$ representa a Temperatura externa do ambiente $\left({ }^{\circ} \mathrm{C}\right) ; T_{\text {int }}$ é a Temperatura interna do ambiente $(\stackrel{\circ}{-} \mathrm{C})$.

Os coeficientes globais de transmitância térmica (U) das paredes, cobertura e janelas da biblioteca foram os mesmos usados para a CT de insolação. Nestes já estão inclusos os coeficientes de convecção interno e externo das superfícies conforme o sentido do fluxo de calor e a velocidade do vento.

\section{Carga Térmica de lluminação $\left(Q_{i l u m}\right)$}

Quanto à iluminação artificial, foram contabilizadas 48 lâmpadas fluorescentes com potência de $110 \mathrm{~W}$. Já a Parte B possui somente 2 lâmpadas de $110 \mathrm{~W}$.

Para efeito de cálculo foi considerado que as lâmpadas ficam 100\% ligadas durante todo o horário de funcionamento da biblioteca, que vai de $07 \mathrm{~h} 30 \mathrm{~min}$ até as $22 \mathrm{~h} 00 \mathrm{~min}$.

\section{Carga Térmica de Equipamentos $\left(Q_{\text {equip }}\right)$}

Na Biblioteca Diva Saraiva, a quantidade de equipamentos ligados ao mesmo tempo varia de acordo com o dia e horário, porém, como a quantidade de equipamentos elétricos na biblioteca é relativamente pequena, para efeito de cálculo, considerou-se que todos os equipamentos ficam ligados durante o período analisado.

$\mathrm{Na}$ Parte A foram contabilizados 11 computadores do modelo desktop, 1 Impressora Laser HP modelo M401DNE, e feito uma estimativa de 10 computadores do 
tipo notebooks. Já a Parte B possui uma estimativa de 2 notebooks. O calor médio dissipado por equipamentos de escritório/biblioteca pode ser verificado na Tab. 5.

Tabela 5. Taxas típicas de dissipação de calor de equipamentos de escritório.

\begin{tabular}{cc}
\hline Equipamentos & Uso contínuo (W) \\
\hline Computadores (com coeficiente de segurança alto) & 75 \\
Monitores (19 a 20 pol.) & 80 \\
Impressoras a laser (tamanho grande, de escritório) & 550 \\
\hline Fonte: Adaptado de NBR 16401-1, 2008.
\end{tabular}

\section{Carga Térmica de Pessoas $\left(Q_{p e s}\right)$}

A Norma Brasileira Regulamentadora (NBR) 16401-1 (2008) mostra uma estimativa de calor sensível e latente liberada por ocupante, de acordo com o nível de atividade e temperatura interna do ambiente. As parcelas de calor sensível e latente podem variar de acordo com a temperatura, mas o calor total dissipado será sempre o mesmo para uma mesma condição de atividade. As taxas típicas de calor liberado por pessoas são mostradas na Tab. 6.

Tabela 6. Taxas típicas de transferência calor liberado por pessoas.

\begin{tabular}{|c|c|c|c|c|}
\hline Nível de atividade & Local & $\begin{array}{c}\text { Calor } \\
\text { Total (W) }\end{array}$ & $\begin{array}{c}\text { Calor } \\
\text { Sensível (W) }\end{array}$ & $\begin{array}{c}\text { Calor } \\
\text { Latente }(\mathrm{W})\end{array}$ \\
\hline Sentado no teatro & Teatro matinê & 95 & 65 & 30 \\
\hline Sentado no teatro, noite. & Teatro noite & 105 & 70 & 35 \\
\hline Sentado, trabalho leve. & $\begin{array}{c}\text { Escritórios, } \\
\text { hotéis. }\end{array}$ & 115 & 70 & 45 \\
\hline
\end{tabular}

Fonte: Adaptado de NBR 16401-1, 2008.

Após uma entrevista com os funcionários da biblioteca, verifica-se na Fig. 6, a estimativa de ocupação da biblioteca ao longo do dia. A capacidade de lotação máxima da Biblioteca Diva Saraiva foi estimada em 84 pessoas, sendo 76 pessoas na Parte A e 8 na Parte B. Para efeito de cálculo foi considerado um valor de ocupação conforme faixas de horário, que pode ser visto na Tab. 7. 


\section{RBCTI}

Figura 6. Ocupação total ao longo do horário de funcionamento da biblioteca.

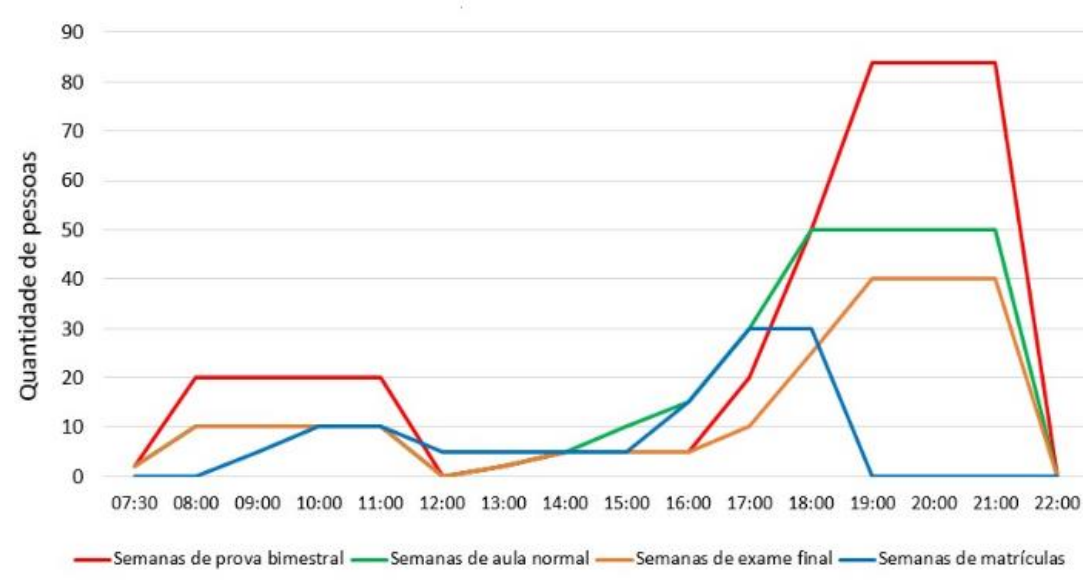

Tabela 7. Ocupação das Partes A e B da biblioteca.

\begin{tabular}{cccc}
\hline Horário $(\mathrm{h})$ & $11 \mathrm{~h}$ até $16 \mathrm{~h}$ & $16 \mathrm{~h}$ até $18 \mathrm{~h}$ & $18 \mathrm{~h}$ até $22 \mathrm{~h}$ \\
\hline Número de pessoas (Parte $\mathrm{A})$ & 10 & 30 & 76 \\
Número de pessoas (Parte $\mathrm{B})$ & 2 & 4 & 8 \\
\hline
\end{tabular}

Segundo a NBR 16401-2 (2008), a sensação de conforto térmico é essencialmente subjetiva, ou seja, varia de pessoa para pessoa. O ambiente está em conforto térmico quando as condições do ar satisfazem pelo menos $80 \%$ dos ocupantes que estejam no recinto a mais de 15 minutos. Como referência, os parâmetros de conforto térmico são mostrados na Tab. 8.

Tabela 8. Parâmetros de conforto térmico.

\begin{tabular}{ccc}
\hline Estação & Temperatura $\left({ }^{\circ} \mathrm{C}\right)$ & Umidade $(\%)$ \\
\hline Verão & 22,5 a 25,5 & 65 \\
Inverno & 21 a 23,5 & 60 \\
\hline
\end{tabular}

Fonte: Adaptado de ABNT 16401-2, 2008.

Como referência para todos os cálculos da CT, foram consideradas as seguintes condições do ar para o ambiente interno da biblioteca: Temperatura de bulbo seco (TBS) $24^{\circ} \mathrm{C}$; Umidade relativa (UR) de $65 \%$.

Carga Térmica de Infiltração/Renovação de $\operatorname{Ar}\left(Q_{\text {inf } / r e n o v}\right)$

A renovação de ar em instalações maiores do que 5 Toneladas de Refrigeração, que equivale à $17,572 \mathrm{~kW}$ é obrigatória independentemente do tipo de ambiente ou do uso, conforme a Portaria 3523/98 do Ministério da Saúde e a Resolução 09 da ANVISA (Agência Nacional de Vigilância Sanitária) de 2003. Estas portarias estabelecem que a vazão mínima para renovação de ar externo seja de $27 \mathrm{~m} 3 / \mathrm{h}$ por pessoa para ambientes com baixa rotatividade de pessoas, que é o caso da Biblioteca Diva Saraiva.

Quando esta renovação é feita somente com adição de ar exterior, ou seja, sem a remoção mecânica de ar interior, a pressão do ar interno do ambiente tende a ser maior que o externo, o que inibe a entrada de ar de infiltração pelas frestas de portas e janelas. 
Segundo Silva (2010), a vazão volumétrica total de ar exterior de renovação é dada pela equação (4).

$$
V_{\text {renov }}=n * V_{\text {pes }}
$$

em que, $V_{\text {renov }}$ representa a Vazão total de ar de renovação $\left(\mathrm{m}^{3} / \mathrm{h}\right) ; n$ é o Número de ocupantes do recinto; $V_{\text {pes }}$ é a Vazão de ar por pessoa $\left(\mathrm{m}^{3} / \mathrm{h}\right)$.

Para o cálculo da vazão de renovação de ar foi considerado que o sistema de renovação da biblioteca trabalhe sempre na vazão máxima para atender o número máximo de ocupantes das partes A e B da biblioteca.

Creder (2004) propõe que as quantidades de transferência de calor sensível e latente que são adicionadas ao ambiente pela infiltração/renovação de ar, são dadas pelas equações (5) e (6).

$$
Q_{\text {sensivel }}=\dot{m} * c p *\left(T_{\text {ext }}-T_{\text {int }}\right)
$$

em que, $Q_{\text {sensível }}$ representa a Quantidade de transferência de calor sensível $(\mathrm{kW})$; $\dot{m}$ é a Vazão mássica de ar de renovação $(\mathrm{kg} / \mathrm{s})$; $c p$ é o Calor específico da água à pressão constante (kJ/kg.K); $T_{\text {ext }}$ é a Temperatura externa do ambiente $(\mathrm{K}) ; T_{\text {int }}=$ Temperatura interna do ambiente (K).

$$
Q_{\text {latente }}=\dot{m} * h_{l v} *\left(\omega_{\text {ext }}-\omega_{\text {int }}\right)
$$

em que, $Q_{\text {latente }}$ representa a Quantidade de transferência de calor latente $(\mathrm{kW})$; $h_{l v}$ é o Calor latente de vaporização da água $(\mathrm{kJ} / \mathrm{kg}) ; \omega_{\text {ext }}$ é a Umidade absoluta do ar externo $(\mathrm{kg} / \mathrm{kg})$ e $\omega_{\text {int }}$ é a Umidade absoluta do ar interno $(\mathrm{kg} / \mathrm{kg})$.

\section{Carga Térmica Total}

Para estimar a Carga térmica total, após calculadas todas as parcelas, o somatório destas representa o valor total da CT do ambiente.

Visando atender às eventuais penetrações de calor no recinto, como medida de segurança, deve-se acrescentar um Coeficiente de Segurança (CS) de 10\% aos cálculos, (CREDER, 2004).

Toda a metodologia de cálculo da CT foi aplicada de forma igual para as três situações críticas de análise: máxima irradiação solar; máxima temperatura externa; máxima ocupação de pessoas. A situação que resulta nos maiores valores de carga térmica, representa a máxima quantidade de calor que precisa ser removida do ambiente, e define a referência do sistema de climatização. Conhecendo-se os detalhes sobre as parcelas da CT, encontram-se características da edificação que podem atenuar ou acelerar a propagação de calor para o interior do ambiente.

\section{RESULTADOS E DISCUSSÃO}

Dentre as três perspectivas de análise, a primeira a ser trabalhada foi a Situação 1 (instantes de máxima irradiação solar). Os cálculos de todas as parcelas da CT da edificação foram feitos levando em consideração todos os parâmetros climáticos, construtivos e de ocupação para estes instantes. 
Os resultados com a carga térmica máxima, média e mínima das Partes $\mathrm{A}$ e $\mathrm{B}$ da biblioteca são mostradas na Tab. 9.

Tabela 9. Carga térmica das Partes A e B para a Situação 1.

\begin{tabular}{lcccc}
\hline & Parte A & Parte A & Parte B & Parte B \\
& CT Total (W) & CT Total com CS $(W)$ & CT Total (W) & CT Total com CS (W) \\
\hline CT Máxima & $3,7432 \times 10^{4}$ & $4,1175 \times 10^{4}$ & $3,6009 \times 10^{3}$ & $3,9610 \times 10^{3}$ \\
CT Média & $2,8913 \times 10^{4}$ & $3,1805 \times 10^{4}$ & $2,6475 \times 10^{3}$ & $2,9123 \times 10^{3}$ \\
CT Mínima & $2,0378 \times 10^{4}$ & $2,2415 \times 10^{4}$ & $1,7214 \times 10^{3}$ & $1,8935 \times 10^{3}$ \\
\hline
\end{tabular}

Percebe-se que a Parte A da biblioteca representa a maior parcela da carga térmica total da edificação, visto que a área de construção, número de pessoas, lâmpadas, equipamentos e vazão de ar de renovação são maiores em comparação à Parte B.

A carga térmica máxima para a Situação 1 ocorreu no dia 03/02/2019 às 13 horas. O gráfico com as parcelas da CT máxima da Parte A, que representa aproximadamente 91\% da carga total, é mostrado na Fig. 7.

Figura 7. Parcelas da carga térmica máxima (W) da Parte A para a Situação 1.

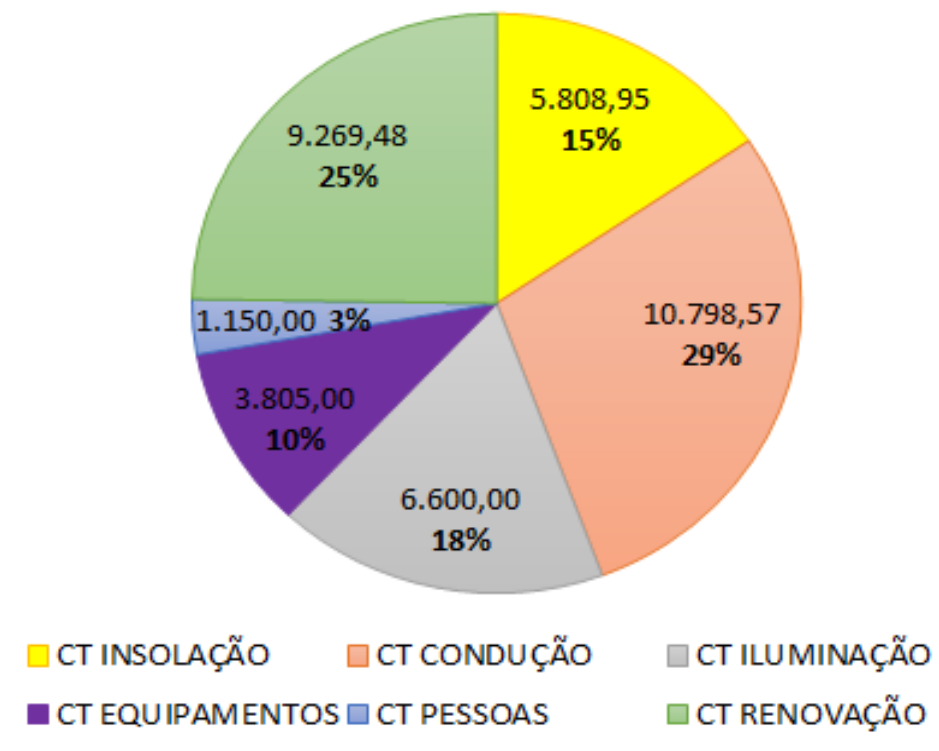

Pôde-se observar pelos resultados que as maiores parcelas da CT são respectivamente condução, renovação de ar e insolação. Percebe-se também que apesar da irradiação solar ser potencialmente maior na Situação 1, a parcela de calor por insolação na envoltória da edificação correspondeu em apenas $15 \%$ da carga térmica total. Fato que pode ser explicado pelos seguintes fatores: biblioteca não receber insolação em todas as superfícies orientadas à NO; baixa absortância solar da cor branco gelo do telhado e baixo coeficiente de transmitância térmica da cobertura; proteções solares externas para janelas nas orientações NE, SE, SO e sombreamento de árvores em NE.

Para a Situação 2 (instantes de máxima temperatura externa) os resultados da CT das partes A e B são mostradas na Tab. 10. 
Tabela 10. Carga Térmica das Partes A e B para a Situação 2.

\begin{tabular}{lcccc}
\hline & $\begin{array}{c}\text { Parte A } \\
\text { CT Total (W) }\end{array}$ & $\begin{array}{c}\text { Parte A } \\
\text { CT Total com CS }(W)\end{array}$ & $\begin{array}{c}\text { Parte B } \\
\text { CT Total (W) }\end{array}$ & $\begin{array}{c}\text { Parte B } \\
\text { CT Total com CS }(W)\end{array}$ \\
\hline CT Máxima & $3,8761 \times 10^{4}$ & $4,2637 \times 10^{4}$ & $3,6001 \times 10^{3}$ & $3,9601 \times 10^{3}$ \\
CT Média & $3,3578 \times 10^{4}$ & $3,6935 \times 10^{4}$ & $3,1318 \times 10^{3}$ & $3,4449 \times 10^{3}$ \\
CT Mínima & $3,0298 \times 10^{4}$ & $3,3328 \times 10^{4}$ & $2,9070 \times 10^{3}$ & $3,1977 \times 10^{3}$ \\
\hline
\end{tabular}

A carga térmica máxima para a Situação 2 ocorreu no dia 19/01/2019 às 15 horas. O gráfico com as parcelas da carga térmica máxima da Parte A é mostrado na Fig. 8.

Figura 8. Parcelas da carga térmica máxima (W) da Parte A para a Situação 2.

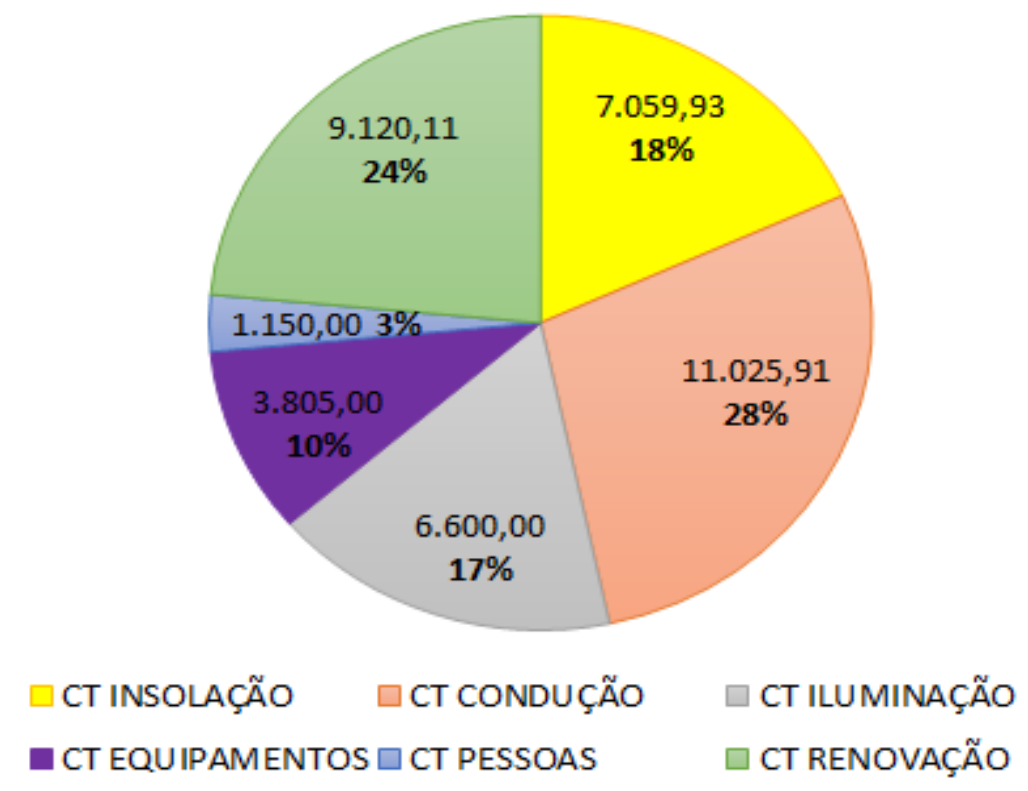

Com estes resultados percebeu-se que a CT máxima para a temperatura foi ligeiramente maior do que na Situação 1. Entretanto, a média e a mínima foram consideravelmente maiores, como observados nas Tab. 9 a 11. Como as quantidades de pessoas, iluminação, equipamentos e vazão de ar de renovação são constantes nas duas situações, evidencia-se que os parâmetros climáticos nos dias de maior temperatura externa contribuem significativamente para uma CT maior.

Nota-se também que a parcela de insolação na Situação 2 foi de $18 \%$ e na Situação 1 de $15 \%$, em que pode ser explicada pela diferença de horários dos instantes medidos. Na Situação 2 a CT máxima ocorreu às 15 horas, onde a incidência maior dos raios solares está sobre a superfície SO. Já na Situação 1, a CT máxima ocorreu às 13 horas, horário em que a irradiação solar incide mais sobre o telhado da biblioteca. Porém, com o bom isolamento imposto pela cobertura da edificação, devido à baixa absorbância solar da cor branca e baixa transmitância térmica dos elementos, esta insolação é consideravelmente atenuada. 


\section{RBCTI}

Para a Situação 3 (instantes de máxima ocupação), foram considerados os dias de maior temperatura externa e o horário das 20 horas, que está entre os instantes de maior ocupação. Os resultados da CT das partes A e B são mostradas na Tab. 11.

Tabela 11. Carga térmica das Partes A e B para a Situação 3.

\begin{tabular}{lcccc}
\hline & Parte A & Parte A & Parte B & Parte B \\
& CT Total (W) & CT Total com CS (W) & CT Total (W) & CT Total com CS (W) \\
\hline CT Máxima & $3,1117 \times 10^{4}$ & $3,4228 \times 10^{4}$ & $2,9425 \times 10^{3}$ & $3,2367 \times 10^{3}$ \\
CT Média & $2,4316 \times 10^{4}$ & $2,6748 \times 10^{4}$ & $2,1334 \times 10^{3}$ & $2,3468 \times 10^{3}$ \\
CT Mínima & $1,6611 \times 10^{4}$ & $1,8272 \times 10^{4}$ & $1,2593 \times 10^{3}$ & $1,3853 \times 10^{3}$ \\
\hline
\end{tabular}

A CT máxima para a Situação 3 ocorreu no dia 22/01/2019 às 20 horas. $O$ gráfico com as parcelas da carga térmica da Parte A é mostrado na Fig. 9.

Figura 9. Parcelas da carga térmica máxima (W) da Parte A para a Situação 3.

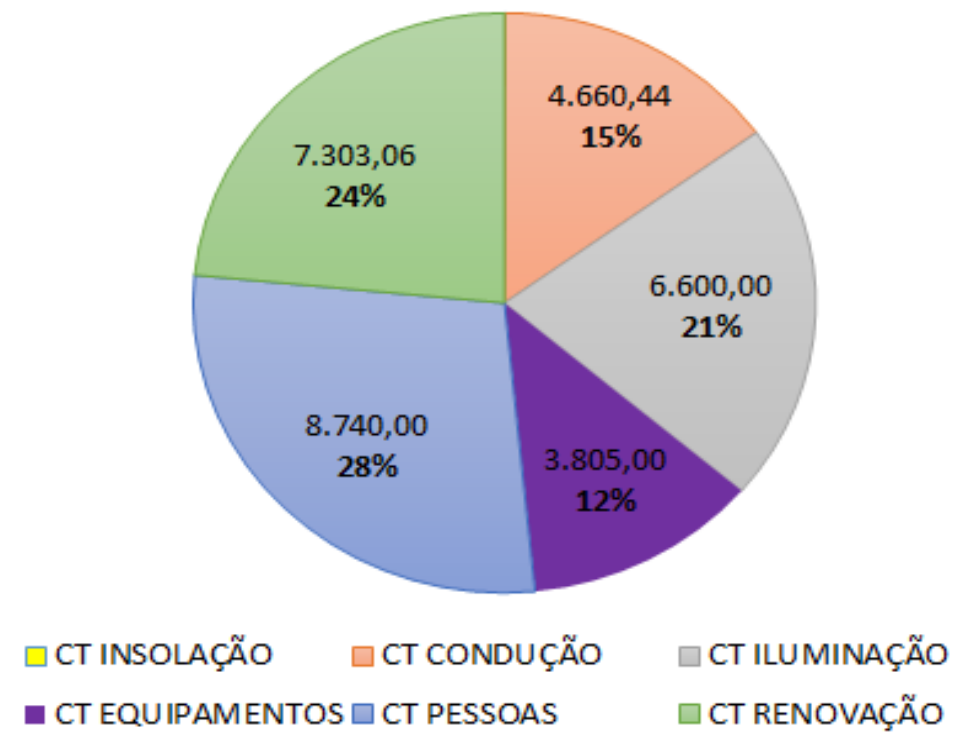

Observa-se pelos resultados que nos instantes de maior ocupação já não há mais a presença da parcela de insolação, visto que no horário das 20 horas a irradiação solar já cessou. A temperatura do ar externo neste horário é menor em relação ao período da tarde, resultando em menor CT de condução e de renovação. Também se nota que devido à máxima ocupação, a maior parcela da CT foi de pessoas.

Para uma melhor perspectiva da importância da análise periódica e detalhada da CT, foi calculada uma hipotética Quarta Situação (Tudo Máximo), onde foram considerados simultaneamente máxima irradiação, temperatura, umidade e ocupação para a biblioteca. Situação que apesar de hipotética, pode muitas vezes ser equivocadamente utilizada por calculistas. A máxima irradiação solar não coincide com o mesmo instante da maior temperatura externa, que também não coincide com o instante de maior ocupação do ambiente. Considerar esses instantes de máxima simultaneamente sem avaliar o devido dia e horário em que ocorrem, leva a um resultado bastante superestimado da CT e fora da realidade da edificação. Os valores calculados da Situação "Tudo Máximo" são mostrados na Tab. 12. 
Tabela 12. Carga térmica da Parte A para a Situação "Tudo Máximo".

\begin{tabular}{lcc}
\hline Parte A & CT Total (W) & CT Total com CS (W) \\
\hline CT Máxima & $5,1026 \times 10^{4}$ & $5,6128 \times 10^{4}$
\end{tabular}

Todas as Cargas Térmicas máximas das quatro situações, para a Parte $A$, são mostradas em ordem decrescente na Fig. 10.

Após a análise de todas as situações, foi definida a Situação 2 como referência para a sugestão do sistema de climatização. Justifica-se pelo fato de que esta situação de cálculo obteve a maior CT tanto para a Parte A, quanto à Parte $B$ da biblioteca, e atendendo a CT da referida situação, todas as outras situações 1 e 3 analisadas também serão contempladas.

Figura 10. Cargas térmicas (W) da Parte A para as quatro situações.

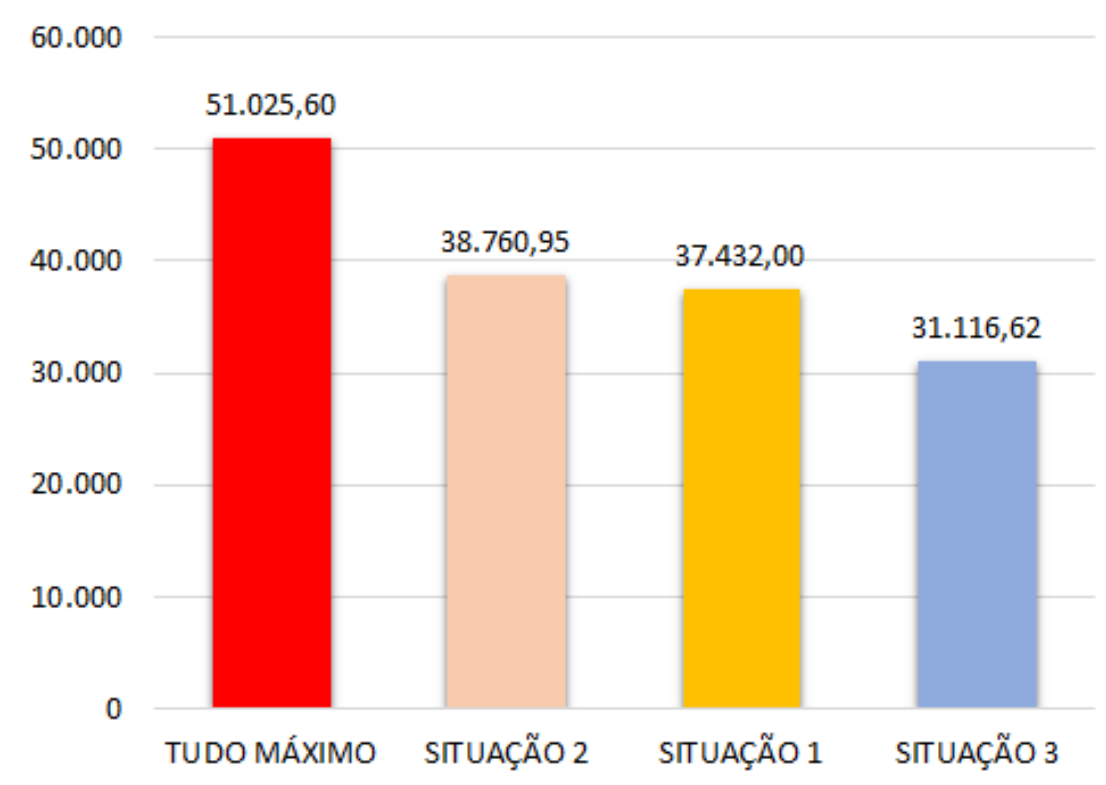

Em sequência da realização de todos os cálculos, definiu-se a potência mínima (BTU/h) e vazão de $\operatorname{ar}\left(\mathrm{m}^{3} / \mathrm{h}\right)$ que precisa ser atendida pelo sistema de climatização, para as partes A e B da biblioteca. A unidade BTU/h foi escolhida pelo fato dos fabricantes de ar-condicionado a utilizarem na especificação dos equipamentos. Estas informações são mostradas na Tab. 13.

Tabela 13. Potência mínima e vazão de ar sugeridos para o sistema de climatização.

\begin{tabular}{cccc}
\hline & Parte A & Parte B & Total \\
\hline Carga Térmica Total $(B T U / h)$ & $145.485,00$ & $13.515,00$ & $159.000,00$ \\
Sensível (BTU/h) & $119.911,00$ & $10.747,00$ & $130.658,00$ \\
Latente (BTU/h) & $25.573,00$ & $2.769,00$ & $28.342,00$ \\
Vazão de ar de renovação $\left(\mathrm{m}^{3} / \mathrm{h}\right)$ & $2.052,00$ & 216,00 & $2.268,00$ \\
\hline
\end{tabular}

Dentre as alternativas de tipos de sistemas de condicionamento de ar foram comparados os sistemas Split, Variable Refrigerant Flow (VRF) e Self-Contained, nos 
parâmetros de potência elétrica consumida e de coeficiente de desempenho (COP), atendendo a potência frigorífica mínima de 159.000,00 BTU/h demandada pela biblioteca. Os valores de cada sistema são mostrados na Tab. 14.

Tabela 14. Potência elétrica consumida e COP.

\begin{tabular}{ccc}
\hline Tipo de sistema & Pot. Elétrica $(\mathrm{W})$ & COP \\
\hline Split & 15,79 & 4,45 \\
VRF & 13,51 & 3,88 \\
Self-Contained & 26,99 & 2,81 \\
\hline
\end{tabular}

Segundo Corrêa (2013), o sistema VRF possui vantagens que, dentre elas, destaca-se a economia de energia proporcionada pelo compressor com variação de capacidade. Esta variação permite que o sistema de climatização se adapte à variação da CT ao longo do dia. Outra característica deste sistema é a facilidade de adaptação à diferentes arquiteturas de construção pelo fato das unidades internas (evaporadoras) serem modulares e haver apenas uma ou poucas unidades externas (condensadoras), trazendo maior simplicidade na montagem e desmontagem numa possível mudança de layout da edificação. Pode-se destacar a eletrônica embutida que permite fixar diferentes temperaturas de conforto para ambientes independentes e o ajuste de horários de funcionamento, podendo também ser controlado remotamente via internet.

Tendo o VRF o menor consumo energético dentre os tipos de sistemas comparados, um COP de 3,88, e todas as vantagens citadas por Corrêa (2013), este sistema de climatização foi o escolhido para a Biblioteca Diva Saraiva.

Para fazer um melhor controle da umidade relativa, foi feito um orçamento com uma empresa de São Paulo-SP, especializada em equipamentos de desumidificação. 0 objetivo foi atender os seguintes parâmetros: umidade relativa em torno de $50 \%$ (TRINKLEY, 2001); área de 402,8 $\mathrm{m}^{2}$ (Parte A, onde ficam as estantes dos livros); pédireito de 3,8 metros; vazão $2052 \mathrm{~m}^{3} / \mathrm{h}$ de ar externo do sistema de ar-condicionado. O dimensionamento realizado pela empresa resultou em 2 equipamentos de desumidificação demonstrados no Quadro 1.

Quadro 1. Equipamentos portáteis de desumidificação de ar.

\begin{tabular}{ccr}
\hline Item & Quant. & Preço Unit. R $\$$ \\
\hline DESIDRAT PLUS 15.000 - 220V (LCD) & 2 & $32.800,00$ \\
\hline VALOR TOTAL $\sum$ (quant. x preço unit.) & $65.600,00$ \\
\hline
\end{tabular}

Em seguida foi desenhado o croqui com a disposição das unidades evaporadoras, condensadora e também das unidades do equipamento de desumidificação na Biblioteca Diva Saraiva. Foi calculado o comprimento das tubulações de interligação das unidades internas com a unidade externa no valor de 63,5 m, como é mostrado na Fig. 11.

$\mathrm{Na}$ etapa subsequente foi realizada a cotação de preços em uma empresa de refrigeração situada na cidade de Uberaba/MG com as especificações do sistema de climatização calculadas para a referida biblioteca. A melhor proposta apresentada mostrou o maior número de informações sobre os componentes necessários à instalação e foi a escolhida para este trabalho. A proposta do fabricante com todos os equipamentos necessários para atender o sistema de climatização é mostrada no Quadro 2. 
Figura 11. Croqui da disposição das unidades.

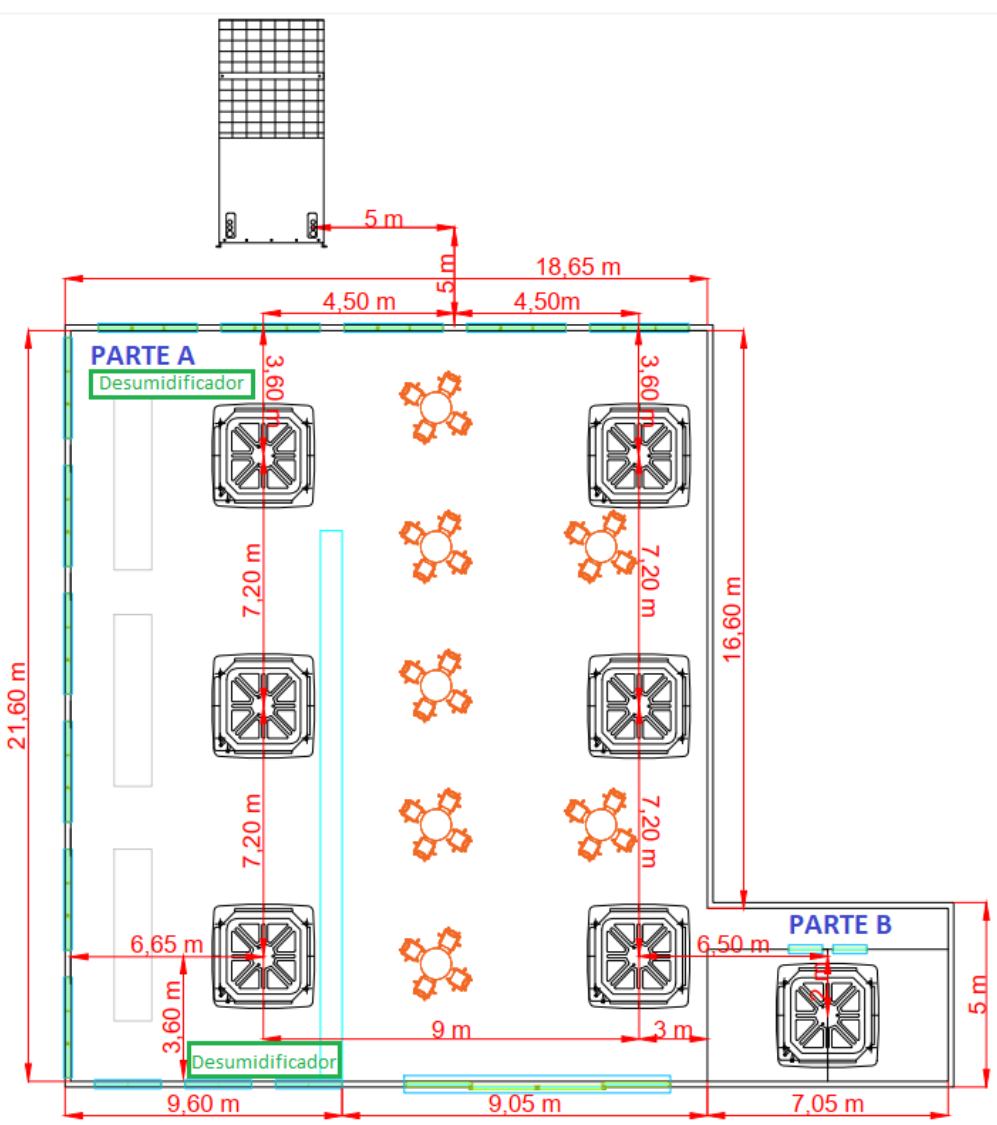

Quadro 2. Proposta comercial do fabricante.

\begin{tabular}{lcr}
\hline \multicolumn{1}{c}{ Item } & Quant. & Preço Unit. R\$ \\
\hline $\begin{array}{l}\text { 4TVH0170D6000AA - Cond. modular 100\% Inverter 170 MBH } \\
\text { 220V/3F - TVR LX R- 410 A }\end{array}$ & 1 & $35.164,00$ \\
4TVC0027B1000AA - Evap. cassete (4 vias) 27 MBH - TVRII R- & 6 & $2.086,00$ \\
410 A, 220V 60HZ 1F & 1 & $1.618,00$ \\
4TVC0018B1000AA - Evap. cassete (4 vias) 18 MBH - TVRII R- & & \\
410 A, 220V 60HZ 1F & 7 & 678,00 \\
RAYPANELWHT001 - Painel branco cassette 4 vias - TVRII & 7 & 138,00 \\
TCONTRM01WA - Controle remoto branco TRANE - TVRII & 6 & 254,00 \\
TRDK225HP - Kit RefNet Evap. de 112 até 225 MBH - TVR & 1 & 474,00 \\
TCONTCCM09A - Controle Central s/ Software/BAS - 64 & & \\
Evaporadores - TVRII & VALOR TOTAL $\sum$ (quant x preço unit) & $57.008,00$ \\
\hline
\end{tabular}

Fonte: TRANE, 2019.

A empresa de refrigeração de Uberaba/MG informou os custos de instalação e manutenção dos equipamentos, que são mostrados no Quadro 3. 
Revista Brasileira de Ciência, Tecnologia e Inovação

Quadro 3. Custos de instalação e manutenção dos equipamentos.

\begin{tabular}{cc}
\hline Descrição & Valor R\$ \\
\hline $\begin{array}{c}\text { Instalação de todas as unidades do sistema, tubulações, parte elétrica e outros, } \\
\text { com todos os materiais necessários inclusos. Startup e orientação quanto ao } \\
\text { funcionamento e operação do sistema. }\end{array}$ & $50.000,00$ \\
Previsão de custo mensal com manutenção preventiva e corretiva. & $2.800,00$ \\
\hline
\end{tabular}

Fonte: TRANE, 2019.

\section{CONCLUSÕES}

Em virtude dos aspectos abordados ao longo do trabalho, a fim de determinar a carga térmica da Biblioteca Diva Saraiva e propor um sistema de climatização, foi possível verificar que a situação de análise que resultou no maior valor de carga térmica total foi a dos instantes de maior temperatura do ar externo, com 38.760,95 W, resultando também no maior valor médio dentre os instantes analisados, 33.577,57 W. Como a temperatura do ar externo está diretamente relacionada com as cargas térmicas de condução e de renovação do ar, esta condição mostrou-se a mais significativa para manter os valores de CT mais elevados.

A situação de análise dos instantes de maior irradiação solar, com média de 28.913,29 W, evidenciou que esta insolação foi atenuada pelos toldos opacos instalados nas superfícies translúcidas e pela baixa absorbância solar da cor branca do telhado.

Os instantes com maior ocupação da biblioteca resultaram no menor valor médio de CT, com 24.316,26 W. Apesar de a carga térmica de pessoas ser maior nesta situação, no horário das $20 \mathrm{~h}$ a temperatura do ar externo é menor em comparação com o período da tarde, e já não há mais a presença da parcela de insolação.

As metodologias utilizadas neste trabalho com a análise de situações críticas, os cálculos realizados hora a hora, e o uso de dados climáticos atuais encontraram resultados que se entende serem os mais aproximados da realidade da edificação.

O sistema de climatização VRF sugerido por este trabalho possui grandes vantagens comparados a outros sistemas de ar-condicionado, que dentre elas destacamse: a possibilidade de renovação; a variação da capacidade do compressor para ajustarse às cargas térmicas parciais; e um menor consumo energético. Na cotação realizada, o custo de aquisição dos equipamentos de ar-condicionado foi de $R \$ 57.008,00$, e o custo de instalação $R \$ 50.000,00$. Também foi orçado o custo mensal com manutenção preventiva e corretiva estimado em $R \$ 2.800,00$. O controle de umidade relativa para preservar os acervos em papel da biblioteca foi cotado em dois equipamentos desumidificadores portáteis de $R \$ 32.800,00$ cada, totalizando $R \$ 65.600,00$. O total calculado para ter-se todos os sistemas instalados e operando foi de $R \$ 172.608,00$.

As análises e os cálculos de carga térmica, a sugestão do sistema de climatização e de desumidificação do ar realizados no presente trabalho apresentaram uma proposta de um ambiente de biblioteca com conforto térmico aos ocupantes, preservação dos livros e demais acervos em papel, atendendo recomendações da literatura e as normas técnicas vigentes do país. 
Revista Brasileira de Ciência, Tecnologia e Inovação

\section{REFERÊNCIAS}

AGÊNCIA NACIONAL DE VIGILÂNCIA SANITÁRIA. ANVISA. Brasília, DF: ANVISA, 2003. Disponível em: <http://www.saude.mg.gov.br/images/documentos/RES_RE_09.pdf>. Acesso em: 21 set. 2019.

ALMEIDA, M. S. A responsabilidade do projetista no controle da umidade. Disponível em: $<$ http://www.engenhariaearquitetura.com.br/2018/09/responsabilidade-do-projetista-no-controleda-umidade>. Acesso em: 08 nov. 2020.

BRAGA, D. K.; AMORIM, C. N. D. Conforto térmico em edifícios residenciais do plano piloto de Brasília. X Encontro nacional de tecnologia do ambiente construído, 18-21 julho, 2004, São Paulo. ISBN 85-89478-08-4.

BRANCO, N. M. L. Avaliação e estudo de medidas de melhoramento do sistema de climatização da Biblioteca das Ciências da Saúde da Universidade de Coimbra. 2016. Dissertação (Mestrado em Engenharia Mecânica). Coimbra, 2016.

CASSARES, N. C. Como fazer conservação preventiva em arquivos e bibliotecas. 5 ed. São Paulo, SP: Arquivo do estado, 2000. 70p.

CORRÊA, B. W.de A. Análise da viabilidade técnica de instalação de um sistema de condicionamento de ar com variação de fluxo de refrigerante (VRF/VRV) para uma unidade da universidade federal do Rio de Janeiro na cidade de Macaé. 2013. 60 f. Trabalho de conclusão de curso-Universidade Federal do Rio de Janeiro, 2013.

CREDER, H. Instalações de ar condicionado. 6 ed. Rio de Janeiro, RJ: Editora LTC, 2004. $318 p$.

FROTA, A B; SCHIFFER, S R. Manual de conforto térmico. 5 ed. São Paulo, SP: Studio Nobel, 2001. 243p.

GOOGLE MAPAS. GOOGLE. Califórnia, EUA: Google Maps, 2019. Disponível em: <https://www.google.com.br/maps>. Acesso em: 12 jul. 2019.

GRANJA, A. D.; LABAKI, L. C. Paredes orientadas a leste e a oeste: uma abordagem crítica em relação ao conforto e à eficiência energética. Revista Ambiente Construído, v. 4, n. 4, p. 65-75, 2004.

HEATING AND AIR CONDITIONING SERVICES \& SYSTEMS. TRANE. Dublin, IRL: TRANE, 2007. Disponível em: https://www.trane.com/Index.aspx. Acesso em: 09 nov. 2019.

INSTITUTO NACIONAL DE METEOROLOGIA. INMET. Brasília, DF: INMET, 2019. Disponível em: <http://www.inmet.gov.br/portal/index.php?r=estacoes/estacoesAutomaticas>. Acesso em:

14 out. 2019.

INSTITUTO NACIONAL DE METROLOGIA. Legislação Inmetro. Rio de Janeiro, RJ: INMETRO, 2013. Disponível em:

<http://www.inmetro.gov.br/legislacao/consulta.asp?seq_classe=1\&sig_classe=RTAC>. Acesso em: 12 ago. 2019. 
LAMBERTS, R.; DUTRA, L.; PEREIRA, F. O. R. Eficiência energética na arquitetura. 3 ed. Rio de Janeiro, RJ: Governo Federal, 2014. 366p.

MINISTÉRIO DA SAÚDE. MS. Brasília, DF: MS, 1998. Disponível em: <https://bvsms.saude.gov.br/bvs/saudelegis/gm/1998/prt3523_28_08_1998.html>. Acesso em: 20 set. 2019.

NARDELLI, T. Métodos para o cálculo da carga térmica. Disponível em: <http://www.engenhariaearquitetura.com.br/2018/01/metodos-para-o-calculo-da-carga-termica>. Acesso em: 07 nov. 2020.

NORMA REGULAMENTADORA BRASILEIRA. NBR 15220. Rio de Janeiro, RJ: ABNTAssociação Brasileira de Normas Técnicas, 2003. Disponível em: <https://www.passeidireto.com/arquivo/1560360/nbr-15220-completa>. Acesso em: 21 set. 2019.

NORMA REGULAMENTADORA BRASILEIRA. NBR 16401-1 Instalações de ar condicionado Sistemas centrais e unitários. Parte 1: Projetos das Instalações. Califórnia, EUA: Slid Share, 2017. Disponível em: <https://pt.slideshare.net/VandernilsonScagion/nbr-16401-1-2008-instalaode-arcondicionadoparte-1>. Acesso em: 18 set. 2019.

NORMA REGULAMENTADORA BRASILEIRA. NBR 16401-2 Instalações de ar condicionado Sistemas centrais e unitários. Parte 2: Parâmetros de conforto térmico. Califórnia, EUA: Scribd. 2019. Disponível em: <https://pt.scribd.com/document/58932136/NBR-16401-2-2008>. Acesso em: 09 out. 2019.

NORMA REGULAMENTADORA BRASILEIRA. NBR-15575 Parte 1 a 6 (completa). Califórnia, EUA: Scribd. 2019. Disponível em: <https://pt.scribd.com/doc/83871060/NBR-15575-Parte-1-a-6completa>. Acesso em: 09 out. 2019.

SACHT, H. M.; ROSSIGNOLO, J. A.; SANTOS, W. N. Avaliação da condutividade térmica de concretos leves com argila expandida. Revista Matéria, v. 15, n. 1, p. 31-39, 2010.

SILVA, Jesué Graciliano da. Introdução à tecnologia da refrigeração e da climatização. 3 ed. São Paulo, SP: Artliber editora, 2010. 179p.

SORGATO, M. J.; MELO, A P; MARINOSKI, D. L.; LAMBERTS, R. Análise do procedimento de simulação da NBR 15575 para avaliação do desempenho térmico de edificações residenciais.

Revista Ambiente Construído, v. 14, n. 4, p. 83-101, 2014.

TRINKLEY, M. Considerações sobre preservação na construção e reforma de bibliotecas: planejamento para preservação. 2 ed. Rio de Janeiro: Projeto Conservação Preventiva em Bibliotecas e Arquivos: Arquivo Nacional, 2001. 